\section{On the edges of the sea}

\author{
John H. Steele
}

Ecology of Coastal Waters: A Systems Approach. By K. H. Mann. Pp.322. Hbk ISBN 0-632-00669-2; pbk ISBN 0-632-00953-5. (Blackwell Scientific/ University of California Press: 1982.) Hbk $£ 25, \$ 36$; pbk $£ 10.80, \$ 18$.

COASTAL ecosystems are very diverse, reflecting the many different ways in which the land interacts with the sea. This coastal zone has always fascinated biologists and, more recently, has become subject to increasing pressure for recreational and commercial uses. Thus, for both scientific and practical reasons, we need to generalize about these environments. Dr Mann's book approaches the problem in two ways - by description of the principal types of coastal ecosystem and by considering the application to these systems of various modelling techniques.

Coastal waters are often considered as the most accessible parts of the pelagic ocean. Here only one chapter is given to phytoplankton-based systems, while most of the text is devoted to excellent analyses of major features such as marshes, mangroves and coral reefs. There is also an emphasis on the sediment communities and their microflora which play a critical role in exchange of materials across the sedimentwater interface and from land to sea.

In particular, Mann focuses on general patterns of energy flow and on average conditions within each system. Although a chapter on water movements is included, there is little on the consequences for these coastal areas of the highly episodic nature of physical changes. Instead, the homeostatic properties of coastal ecosystems are a central feature of the approach used in this book. As Mann acknowledges, further work will be needed to assess these properties in the context of extremes of variability to which they are exposed.

The final chapter, "Models and Management", brings together methods of synthesizing and using ecosystem studies in the coastal zone. The author discusses several computer simulations which attempt to reconstruct the system numerically from its physical, chemical and biological components. The general conclusion is that these exercises give valuable insights, but are far from being a predictive tool for environmental managers. Mann points out that the managerially useful models, such as those for biological oxygen demand in estuaries, would be considered by many researchers as unrealistic simplifications. The broad question he raises is whether simpler holistic models without explicit formulation of organism behaviour are not merely of empirical value, but a recognition of a general feature of the hierarchies within and between ecosystems. This question is not new, nor confined to the coastal area, but it is central to both the future research and management philosophy for this part of our environment.

Ecology of Coastal Waters combines sound descriptive chapters with proper speculative flavouring. It is aimed at advanced students and professionals, and will be useful and interesting to all concerned with the edges of the sea.

John H. Steele is Director of the Woods Hole Oceanographic Institution, Massachusetts.

\section{Galileo rules, OK?}

\section{J. S. Clarke}

Retarded Action-at-a-Distance: The Change of Force with Motion. By G. Burniston Brown. Pp.145. ISBN 0-90437814-4. (Cortney Publications, 95-115 Windmill Road, Luton, UK: 1982.) $£ 9.95$.

IT is in the nature of science to question, to refuse to treat anything as unalterable dogma; and so there is nothing improper in questioning the correctness of Maxwellian electrodynamics, special relativity and general relativity, as does the author of this book. In their place he proposes Euclidean space and time, with Galilean relativity, combined with retarded inter-particle action at a distance using unconventional force-laws. It is a polemical book, and so one looks for a clear critique of the central philosophical and experimental points where he differs from conventional wisdom. But one looks in vain: the experimental evidence is ignored, the philosophical arguments evaded.

For example, in his theory electromagnetic interactions are linear and linked to the Euclidean geometrical relations between the particles involved; thus it is crucial that a null result be obtained for the "gravitational bending of light" experiment. And so it is astonishing that his only reference on this subject is to a 1930 article criticizing the "early claims that the effect of gravitation on light at eclipses had been proved"; as if the author were unaware of the work of Counselman, Fomalont and Sramek that improved on the early eclipse observations by an order of magnitude in accuracy.

\section{Gaia anew}

J.E. Lovelock's Gaia: $A$ New Look at Life on Earth (reviewed in Nature 282, 154; 1979) has now appeared in a paperback edition. The book is published by Oxford University Press, price $£ 2.95$.
The crucial difficulty with any direct action theory is the explanation of radiation-reaction, as manifested in the behaviour of charged particles in accelerators. It was this difficulty that led Wheeler and Feynman to propose their time-symmetric direct action theory, explicitly rejected by the author. Yet he concerns himself almost exclusively with phenomena such as current electricity, where it is possible to avoid the problem, and nowhere gives a clear account of radiation-reaction on individual particles.

The treatment of philosophical issues is no more satisfactory. The author is proposing a Galilean structure for spacetime, but without any serious philosophical justification whatever. One supposes that he holds to the Kantian view that the Euclidean nature of space is part of its $a$ priori status; but Kant was writing before Poincaré, Reichenbach and Gruenbaum, and before the Eortvös-type experiments of Dicke and Braginsky on which the relativistic concept of space is nowadays based. Dr Burniston Brown is writing after these writers and experimentalists have shown that it is far from obvious that the "space" used by astronomers is necessarily Euclidean. In 1880 this book might been a useful contribution. In 1982 it is conspicuous only by its omissions.

C. J. S. Clarke is a Lecturer in Mathematics at the University of York.

\section{"THE MOST COMPLETE HISTORY OF THE ATOM TO BE PUBLISHED" Energy Daily}

The Atomic Complex, by Bertrand Goldschmidt is an accurate, complete and fascinating worldwide political history and personal memoir of nuclear energy - from the development of the bomb in World War Il to today's nuclear energy complex and proliferation problems.

Goldschmidt, a leading French scientist turned international statesman, reviews half a century of political moves, countermoves, international intrigue and manipulation. The Atomic Complex is a pragmatic look at the nuclear world today, care. fully examining the terror nulear weapons represent, but at the same time stressing the benefits of nuclear energy. Order this $\mathbf{5 0 0}$ page best seller today..." superbly done and reads easily."

\section{$\$ 31$ Hardbound $\$ 24$ Softbound}

American Nuclear Society 555 North Kensington Avenue La Grange Park, IL 60525 USA 